\title{
Determination of the Potentiostatic Stability of PEMFC Electro Catalysts at Elevated Temperatures
}

\author{
V.A.T. Dam \\ K. Jayasayee \\ F.A. de Bruijn
}

December 2009

ECN-W--09-053

Published in Fuel Cells 09, 2009 , no. 4, 453-462 



\title{
Determination of the Potentiostatic Stability of PEMFC Electro Catalysts at Elevated Temperatures ${ }^{\wedge}$
}

\author{
V. A. T. Dam ${ }^{1,3}$, K. Jayasayee ${ }^{1}$, F. A. de Bruijn ${ }^{1,2 *}$ \\ ' Chemical Engineering and Chemistry, Eindhoven University of Technology P.O. Box 513,5600 MB Eindhoven, The Netherlands \\ 2 Energy Research Centre of the Netherlands (ECN), P.O. Box 1, 1755 ZG, Peiten, The Netherlands \\ 3 Present adress: IMEC-NL/Holst Center, P.O. Box 8550, 5605 KN Eindhoven, The Netherlands
}

Received October 30, 2008; accepted May 1 1, 2009

\begin{abstract}
The electrochenucal stability of platinum on carbon catalyst (Hispec TM 4000 , Johnson Matthey) has been investigated predominantly at constant potentials ranging from 0.95 to $1.25 \mathrm{~V}$ at elevated temperatures. By combining a quartz crystal microbalance (OCM) with electrochemical techniques, dynamic insight is obtained on the oxidation and corrosion of both platinum and carbon during potentiostatic hold. From the cyclic voltammetry (CV) data, it can be concluded that at all conditions, the platinum surface area decreases when Pt on carbon catalysts are exposed to a constant poten tial of 1.05 to $1.25 \mathrm{~V}$. Under the applied conditions, this loss
\end{abstract}

of surface area is primarily caused by the dissolution of pla tinum:

Both the QCM as well as on-line electrochemical mass spectrometry (OLEMS) experiments show that the corrosion of carbon is catalysed by the presence of platinum at $80 \% \mathrm{C}$ as long as the platinum surface is not passivated by an oxide layer.

Keywords: Carbon, Corrosion, Dissolution, PEMFC, Platinum

\section{Introduction}

The stability of the electrodes in proton exchange membrane fuel cells (PEMFCs) depends on several factors such as noble metal composition, type of carbon support, the preparation procedure, cathode potential and operating temperature. The degradation of any individual element of the electrode can lead to a decrease in performance of the whole electrode system and subsequently influences the fuel cell performance [1]. For platinum supported on carbon catalysts, the dissolution of platinum leads to a reduction of the electrochemical active surface area which will generally lead to a loss of PEMFC performance in time. The Pt loss takes place especially when high electrode potentials occur during shutdown of the fuel cells [2-8] or under fuel starvation $[9,10]$. Besides the degradation as caused by dissolution and redeposition of platinum, the stability of platinum particles in

\footnotetext{
- Paper presented at the MEA'08 Conference, La Grande Motte, 21 st-24th September 2008.
}

the catalyst also depends on the surface chemistry of the support $[6,11-16]$. The stability of platinum on supported carbon has been studied depending on platinum loading [17], carbon morphology [18] and operating conditions such as humidity and potential [12, 19-22]. In addition, the corrosion of the carbon support has a strong impact on the catalyst stability and significantly reduces its activities [23,24].

At cell potentials lower than $1.2 \mathrm{~V}$, in acidic medium at elevated temperature, carbon (Vulcan XC-72) can already be oxidised to form a wide variety of carbon surface oxides such as quinone/hydroquinone and CO groups at the surface, that reduce the hydrophobicity and influence the conductivity and catalytic activity of the catalyst layer [25]. The corrosion of carbon to form $\mathrm{CO}_{2}$ under start-up and shutdown conditions, where the cell potential increases above $1.2 \mathrm{~V}$ has already been reported in [26]. Experiments at $1.2 \mathrm{~V}$ versus RHE suggested a fast increase in surface oxides during the first $16 \mathrm{~h}$ and a slower increase thereafter. The decrease in the

["] Corresponding author, debruijn@ecn.nl 
corrosion rate in time has been observed in several studies $[19,23,27]$.

It has been shown in $[17,28,29]$ that the presence of platinum accelerates the corrosion of the carbon support, and that the corrosion rate depends on the platinum loading. The onset potential at which carbon is oxidised to $\mathrm{CO}_{2}$ as measured by mass spectroscopy, reduced from 1.1 to $0.55 \mathrm{~V}$ versus RHE when the platinum loading increased from 0 to $39 \%$. In addition it has been found that the amount of $\mathrm{CO}_{2}$ generated at a certain potential, higher than $0.9 \mathrm{~V}$ versus RHE, increases with increasing loading of platinum. The influence of $\mathrm{Pt}$ on the carbon corrosion becomes less pronounced at temperature higher than $50^{\circ} \mathrm{C}$ [29]. It was shown in [23] that at $80^{\circ} \mathrm{C}$ the presence of $\mathrm{Pt}$ does not significantly increase the carbon corrosion rate. It does nonetheless accelerate the rate of quinone/hydroquinone production.

In this paper, the electrochemical stability of much used platinum on carbon catalyst (Hispec 4000, Johnson Matthey) is investigated predominantly at potentiostatic conditions at elevated temperatures. By combining a quartz crystal microbalance $(\mathrm{QCM})$ with cyclic voltammetry $(\mathrm{CV})$ and on-line electrochemical mass spectrometry (OLEMS), the oxidation and corrosion of both platinum and carbon during potentiostatic hold have been measured in situ.

\section{Experimental}

\subsection{Pt/C and Carbon Electrode Preparation}

The stability of $\mathrm{Pt}$ on supported carbon is determined on an electrode consisting of an unpolished gold/Ti quartz crystal substrate covered by a either a thin layer of Pt supported on carbon $\left(\mathrm{Pt} / \mathrm{C}\right.$ ) mixed with $\mathrm{Nafion}{ }^{\circledR}$ or a thin layer of carbon mixed with Nafion. For $\mathrm{Pt} / \mathrm{C}$, this configuration was obtained by applying a catalyst ink, a mixture of $\mathrm{Pt} / \mathrm{C}$ (XC72R) (Hispec 4000, Johnson Matthey) which contains $40 \mathrm{wt} . \% \mathrm{Pt}$, and Nafion dispersed in 1,2 propanediol on a $1.37 \mathrm{~cm}^{2}$ Maxtek gold quartz crystal electrode suitable for working at elevated temperature. After the application of the ink, the electrode was dried for at least one day at room temperature, and subsequently one hour at $120^{\circ} \mathrm{C}$ in air. For experiments on the carbon support, the same procedure was used, by replacing the $\mathrm{Pt}$ on Vulcan by Vulcan XC72R. The final electrodes contain 55 wt. $\%$ catalyst (either $\mathrm{Pt} / \mathrm{C}$ or $\mathrm{C}$ ) and 45 wt.-\% Nafion.

\subsection{Electrochemical Measurements in Combination with Quartz Crystal MicroBalance (QCM)}

Electrochemical experiments are performed in a thermostatted electrochemical cell in which the $\mathrm{Pt} / \mathrm{C}$ covered quartz crystal electrode acted as a working electrode, a Pt disk as counter electrode and a Redrod reference electrode (Radiometer Analytical) with a sleeve junction was used as reference electrode. An Ecochemie Autolab PGSTAT 30 potentiostat was used to control the potential. All electrode potential values in this paper are reported verstus the reversible hydrogen electrode (RHE). In this setup the working electrode, which is at the same time an electrode for the microbalance, was separated from the counter electrode by a glass membrane. The volume of the compartment for the working electrode was about $230 \mathrm{~mL}$.

All electrochemical experiments are done in $1 \mathrm{M} \mathrm{HClO}_{4}$ which was prepared from chloride free $\mathrm{HClO}_{4} 70 \%$ (Suprapur, Merck) and ultra pure $18 \mathrm{M} \Omega \mathrm{cm}$ Millipore water. Before the experiment, the electrolyte was purged with purified Argon ( $>99.999 \%$ ) to remove dissolved oxygen.

The Maxtek PM 710 quartz microbalance monitor and the crystal used were specially selected for experiments between 40 and $80^{\circ} \mathrm{C}$. The resonant frequency of the crystal amounted to $5 \mathrm{MHz}$. The angle of cut, being between $35^{\circ} 14^{\prime}$ and $35^{\circ} 22^{\prime}$ is such that the temperature coefficient of the electrode is zero between 40 and $80^{\circ} \mathrm{C}$.

As a relation between the mass change, $\Delta m$, and the change in the resonance frequency, $\Delta f$, of the quartz crystal is calculated by the Sauerbrey equation [30]:

$\frac{\Delta m}{\Delta f}=-\frac{\left(\mu_{\mathrm{q}} \rho_{\mathrm{q}}\right)^{1 / 2}}{\left(2 f_{0}^{2}\right)}$

where $f_{0}$ is the resonant frequency, $\rho_{\mathrm{q}}$ is the density and $\mu_{\mathrm{q}}$ is the shear modulus of the quartz crystal. For this quartz electrode, by substituting $f_{0}=5 \times 10^{6} \mathrm{~Hz}, \rho_{\mathrm{q}}=2.648 \mathrm{gcm}^{-3}$ and $\mu_{\mathrm{q}}=2.947 \times 10^{11} \mathrm{gcm}^{-1} \mathrm{~s}^{-2}$ into Eq. (1), the value of $\Delta m / \Delta f=-1.767 \times 10^{-8} \mathrm{gcm}^{-2} \mathrm{~Hz}^{-1}$. This value is further used to calculate the amount of the mass gain or loss during the oxidation and dissolution process.

Because the electrochemical cell including the QCM electrode is thermostatted during the experiment, the influence of the temperature and viscosity changes on the frequency is neglected.

Prior to the determination of the $\mathrm{Pt} / \mathrm{C}$ or carbon stability, the electrode is equilibrated in distilled water for at least 5 days to allow for full hydration of Nafion in the catalyst layer. During this pre-treatment, in the first $24 \mathrm{~h}$ the mass increase in the electrodes containing $250-500 \mu \mathrm{g}$ of catalyst amounts to $5 \mu \mathrm{g} \mathrm{h}^{-1}$, and levels off to a continuous linear mass increase amounting to $0.03 \mu \mathrm{g} \mathrm{h}^{-1}$ for the next $180 \mathrm{~h}$. The QCM data shown aren't corrected for this baseline mass increase. Only mass changes higher than $0.1 \mu \mathrm{g} \mathrm{h} \mathrm{h}^{-1}$ are considered as caused by electrochemically induced processes.

The stability of $\mathrm{Pt} / \mathrm{C}$ and carbon was studied at constant potential in the range from 0.95 to $1.25 \mathrm{~V}$ versus RHE at $80^{\circ} \mathrm{C}$. For each measurement a fresh electrode was prepared. Fresh $\mathrm{Pt} / \mathrm{C}$ electrodes were characterised by $\mathrm{CV}$, in a potential range from 0.05 to $1.3 \mathrm{~V}$ versus $\mathrm{RHE}$ at a sweep rate of $50 \mathrm{mV} \mathrm{s}^{-1}$. Fresh carbon electrodes were characterised in a potential range between 0.05 and $1.0 \mathrm{~V}$ versus RHE.

The potential scan range for carbon was limited to $1.0 \mathrm{~V}$ to prevent excessive oxidation of the carbon during the characterisation itself, while for $\mathrm{Pt} / \mathrm{C}$ the scan range was extended 
to $1.3 \mathrm{~V}$ in order to enable the full characterisation of the platinum surface, including the determination of the peak potential for platinum oxide reduction.

For experiments on carbon electrodes, the double layer current at $650 \mathrm{mV}$ versus RHE in the anodic sweep was used to calculate the surface area of the carbon electrode at the start of the experiment. A value of $8 \mu \mathrm{F} \mathrm{cm} \mathrm{cm}^{-2}$ was taken for the double layer capacity of Vulcan XC72R as was determined by Kinoshita and Bett [25].

The stability of the $\mathrm{Pt} / \mathrm{C}$ or carbon electrode was studied at a constant electrode potential by applying a step potential from $0.45 \mathrm{~V}$ to the required potential while the electrode weight was simultaneously monitored with the quartz microbalance. The mass of the electrode is set at zero immediately after the step potential was applied. The potentiostatic experiments were interrupted for characterisation of the electrode by $\mathrm{CV}$. While the stability of carbon was studied both at 60 and $80^{\circ} \mathrm{C}$, the stability of $\mathrm{Pt} / \mathrm{C}$ was only studied at $80^{\circ} \mathrm{C}$, except for a single experiment at $60^{\circ} \mathrm{C}$ and $1.05 \mathrm{~V}$.

\subsection{Electrochemical Measurements in Combination with On-Line Electrochemical Mass Spectrometry (OLEMS)}

Using OLEMS, the formation of $\mathrm{CO}_{2}$ as a function of potential was determined for $\mathrm{Pt} / \mathrm{C}$ and carbon electrodes similar to those used in the QCM study. Due to the limited long-term stability of the mass signal, only linear sweep experiments were performed. In a setup, described in [31], the mass signal of $\mathrm{CO}_{2}(\mathrm{~m} / \mathrm{z}=44)$ was measured by the detection of gaseous products at the working electrode through a porous PEEK tip holder placed at a distance of 20-30 $\mu \mathrm{m}$ from the working electrode. All experimental conditions and electrode preparations were exactly the same as described in the previous sections. The scan rate used during the OLEMS experiments was $10 \mathrm{mV} \mathrm{s}^{-1}$, to minimise the influence of the delay between the electrochemical condition and the recorded mass signal.

\subsection{Catalyst Characterisation by Transmission Electron Microscopy (TEM)}

Two electrode samples, one of a freshly prepared electrode and one after exposure to $1.05 \mathrm{~V}$ at $80^{\circ} \mathrm{C}$, were analysed using TEM. The electrode samples were removed from the QCM electrode holder with 2-propanol. The scrapped catalysts were grinded on an agate mortar with 2-propanol. The catalyst dispersed in 2-propanol was then ultrasonicated for a few minutes to reduce the particle agglomeration, and mounted on a carbon coated copper grid (200 mesh), the solvent was allowed to evaporate at room temperature. The TEM analysis was performed on a Technai-sphera microscope using a voltage of $200 \mathrm{kV}$. The particles size distribution in both samples was determined by counting at least 100 particles from at least 3 different parts of the electrode sample.

\section{Results and Discussion}

\subsection{The Stability of Carbon}

\subsubsection{Characterisation of Fresh Carbon Electrodes by Cyclic Voltammetry (CV), QCM and OLEMS}

The cyclic voltammogram of fresh Vulcan XC72R in $1 \mathrm{M}$ $\mathrm{HClO}_{4}$ at a potential range between 0.05 and $1 \mathrm{~V}$, as recorded at room temperature, is shown in Figure 1. Only the charging of the electrical double layer of the carbon/electrolyte interface is observed under these conditions, indicating the absence of redox species on the carbon surface, as well as that scanning the electrode up to $1.0 \mathrm{~V}$ at room temperature does not lead to the formation of new redox couples such as the well-known quinone/hydroquinone couple.

The mass of electrode, shown in the same Figure 1, which is simultaneously recorded during potential cycling, shows a minimum at a potential of $0.45 \mathrm{~V}$. The mass increase during scanning from 0.45 to $1.0 \mathrm{~V}$ can be attributed to the reversible adsorption of oxygen atoms. The mass increase during scanning downwards from 0.45 to $0.05 \mathrm{~V}$ is somewhat surprising, and amounts to as much as $75 \%$ of the mass gain in the potential range from 0.45 to $1.0 \mathrm{~V}$. The most likely explanation for this mass gain is the adsorption of water molecules, as the adsorption of hydrogen between 0.05 and $0.45 \mathrm{~V}$ could never lead to a comparable mass gain as caused by hydroxide or oxide adsorption in the potential range between 0.45 and $1 \mathrm{~V}$, while the $\mathrm{ClO}_{4}^{-}$ions should be repelled when scanning in negative direction. The minimum at $0.45 \mathrm{~V}$ could be an indication that the potential of zero charge of the carbon surface is at $0.45 \mathrm{~V}$.

From the cyclic voltammogram of the fresh carbon electrode, the double layer capacity of the electrode can be calculated. Using $8 \mu \mathrm{F} \mathrm{cm}^{-2}$ for the double layer capacity of Vulcan $\mathrm{XC72R}$ as was determined by Kinoshita and Bett [25], the surface area of the carbon electrode could be calculated. Dividing this by the mass of electrode applied on the QCM substrate, an electrochemically active surface area between 120

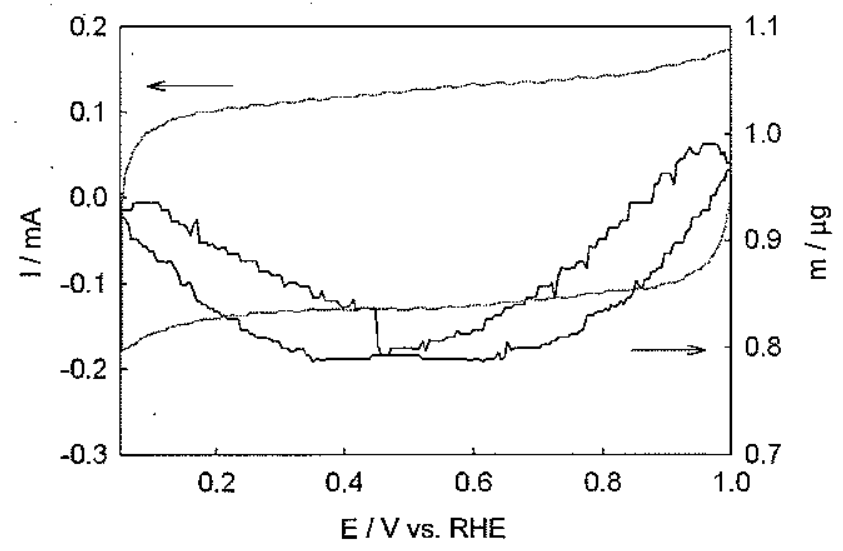

Fig. 1 Cyclic voltammogram and QCM mass signal of carbon support Vulcan XC $72 R$, taken at a scan rate of $50 \mathrm{mV} \mathrm{s}^{-1}$ in $1 \mathrm{M} \mathrm{HClO}_{4}$ at room temperature. 
and $180 \mathrm{~m}^{2} \mathrm{~g}^{-1}$ was obtained for the Vulcan $\mathrm{XC72R}$ carbon. This value corresponds to $50-75 \%$ utilisation of as received carbon.

Figure 2 shows the mass signal of $\mathrm{CO}_{2}$ $(m / z=44)$ for the Vulcan XC72R carbon support, as a function of the electrode potential at $80^{\circ} \mathrm{C} . \mathrm{CO}_{2}$ formation during a linear sweep at these conditions starts at $1.1 \mathrm{~V}$ versus RHE.

\subsubsection{The Stability of Carbon Under Potentiostatic Conditions}

The recorded mass signals for the carbon support versus time as function of electrode potential and temperature are given in Figure 3 . At $60^{\circ} \mathrm{C}$, only at a potential of $1.15 \mathrm{~V}$, a decrease in the electrode mass could be ob-
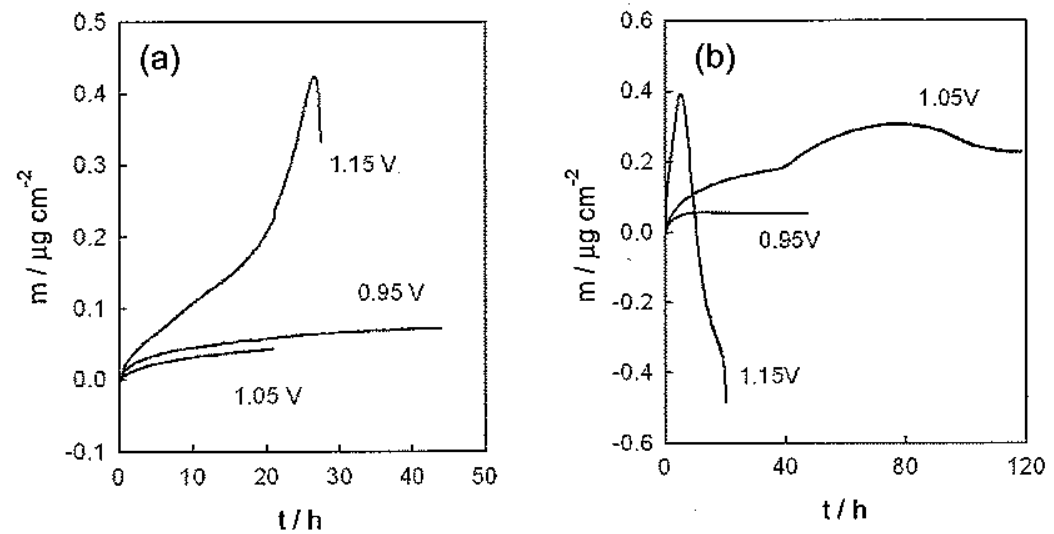

Fig. 3 Time dependence of the electrode mass measured at $0.95,1.05$ and $1.15 \mathrm{~V}$ for carbon support Vulcan XC $72 R$, normalised on the carbon surface area as determined from the double layer capacitance: (a) at $60^{\circ} \mathrm{C}$; (b) at $80^{\circ} \mathrm{C}$. served. The mass change as observed at 0.95

and $1.05 \mathrm{~V}$ is comparable to the mass change when no potential is applied, and that is attributed to the slow uptake of water. The mass increase at $1.15 \mathrm{~V}$, is much steeper, and can be attributed to the formation of oxygenated species on the carbon surface. At $80^{\circ} \mathrm{C}$ at potentials of $1.05 \mathrm{~V}$ and higher, the mass signal increase deviates from that attributed to the uptake of water.

Carbon can be oxidised to quinone/hydroquinone, $\mathrm{CO}$ or $\mathrm{CO}_{2}$ according to Eqs. (2)-(5) $[25,29,30,32]$ :

$$
\begin{array}{cc}
6 \mathrm{C}+2 \mathrm{H}_{2} \mathrm{O} \rightarrow \mathrm{C}_{6} \mathrm{H}_{4} \mathrm{O}_{2} & \mathrm{E}=0.6 \mathrm{~V} \\
\mathrm{C}_{6} \mathrm{H}_{4} \mathrm{O}_{2}+4 \mathrm{H}_{2} \mathrm{O} \rightarrow 6 \mathrm{CO}_{\text {surf }}+12 \mathrm{H}^{+}+12 \mathrm{e}^{-} \mathrm{E}=0.6 \mathrm{~V} \\
\mathrm{CO}_{\text {surf }}+\mathrm{H}_{2} \mathrm{O} \rightarrow \mathrm{CO}_{2}+2 \mathrm{H}^{+}+2 \mathrm{e}^{-} & \mathrm{E}=0.8 \mathrm{~V} \\
\text { Net reaction: } \mathrm{C}+2 \mathrm{H}_{2} \mathrm{O} \rightarrow \mathrm{CO}_{2}+4 \mathrm{H}^{+}+4 \mathrm{e}^{-} & \mathrm{E}=0.8 \mathrm{~V}
\end{array}
$$

The total mass gained at these potentials, amounts to around a factor 6 of the original mass of carbon exposed to the surface, meaning that neither the formation of quinone,

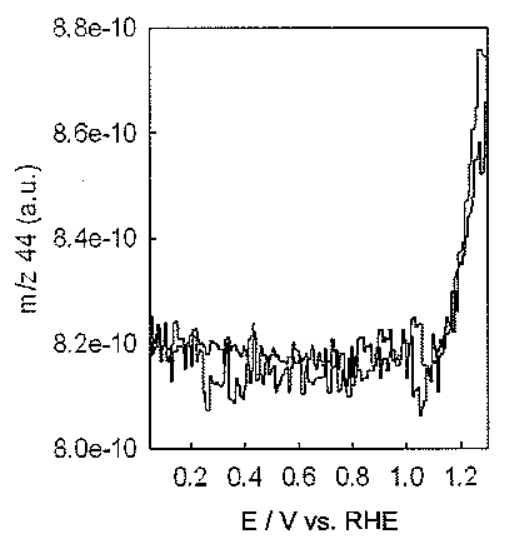

Fig. 2 OLEMS of carbon support Vulcan XC 72R, taken at a scan rate of $10 \mathrm{mV} \mathrm{s}^{-1}$ in $1 \mathrm{M} \mathrm{HClO}_{4}, 80^{\circ} \mathrm{C}$. which would lead to a mass increase of $50 \%$, nor that of adsorbed CO, which would lead to a mass increase of $130 \%$, can explain this mass increase. A more likely explanation is that the surface becomes more positively charged upon oxidation, and by that, leads to the attraction of $\mathrm{ClO}_{4}^{-}$ions.

Both at 60 and $80^{\circ} \mathrm{C}$, and at $1.15 \mathrm{~V}$, a sharp decrease in the mass can be observed, which can be attributed to the formation of $\mathrm{CO}_{2}$, with the concomitant desorption of $\mathrm{ClO}_{4}{ }^{-}$ions. This is in line with the OLEMS results, which showed the formation of $\mathrm{CO}_{2}$ at potentials higher than $1.1 \mathrm{~V}$ at $80^{\circ} \mathrm{C}$. The fact that in the OLEMS setup, $\mathrm{CO}_{2}$ could be observed during the linear sweep, while the mass only starts to decrease after $5 \mathrm{~h}$ at the same conditions, can be explained by the high sensitivity of the mass spectrometer for small amounts of $\mathrm{CO}_{2}$, which is apparently produced while on average the electrode is gaining mass due to the formation of oxygenated species.

When a cyclic voltammogram is recorded after the potentiostatic hold of the carbon electrode at $60^{\circ} \mathrm{C}$, the oxidationreduction peak at around $0.5 \mathrm{~V}$, generally attributed to the hydroquinone/quinone redox couple, is clearly formed, as shown in Figure 4. The area of the redox peak is after exposure to $1.15 \mathrm{~V}$ considerably larger than after the same potentiostatic hold time at $1.05 \mathrm{~V}$.

\subsection{The Stability of Platinum on Carbon}

\subsubsection{Characterisation of Fresh $P t / C$ Electrodes by Cyclic Voltammetry (CV), QCM and OLEMS}

The cyclic voltammogram of a $\mathrm{Pt}$ on carbon electrode before starting a potentiostatic experiment is presented in Figure $5 \mathrm{a}$. From this $\mathrm{CV}$, the real surface area of the platinum is calculated from the charge of the hydrogen desorption region, assuming $0.210 \mathrm{mC}$ per 'real' square centimetre of Pt, after subtracting the double layer charge. The change of the electrode mass of this $\mathrm{Pt} / \mathrm{C}$ electrode, per square centimetre of platinum, which is simultaneously recorded during the cyclic voltammogram, is presented in Figure $5 \mathrm{~b}$. In the same 

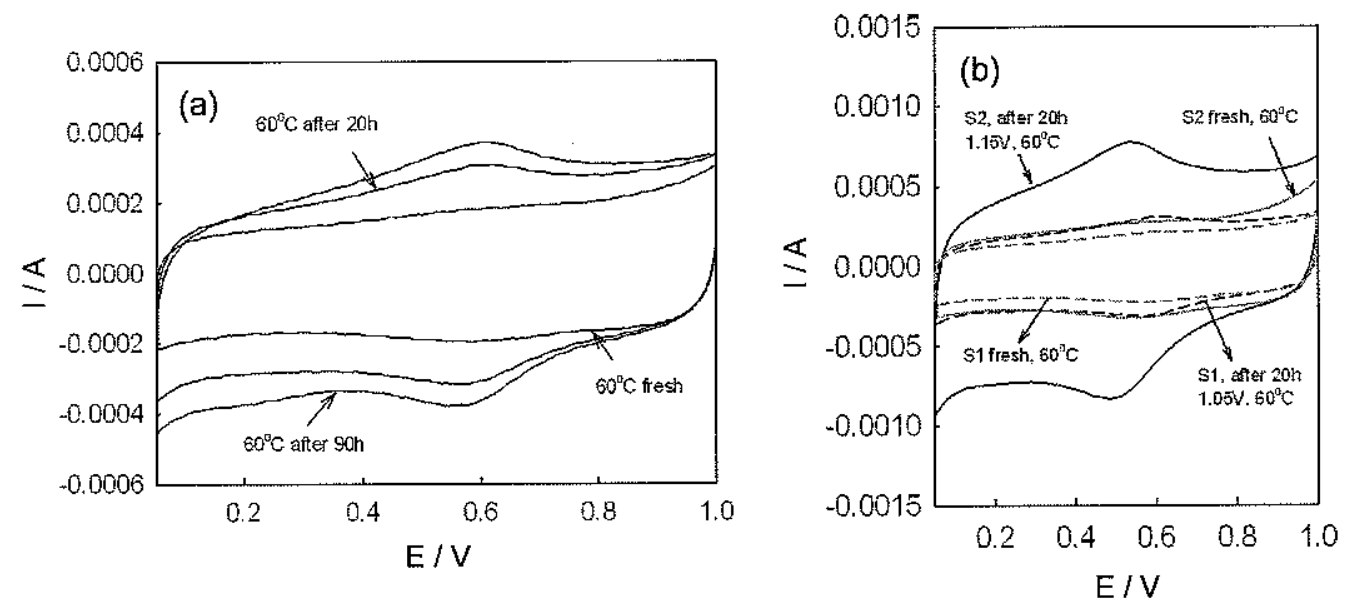

Fig. 4 Cyclic voltammograms of carbon taken at a scan rate of $50 \mathrm{mV} \mathrm{s}^{-1}$ before and after exposure to a constant potential at $60^{\circ} \mathrm{C}$ : (a) intluence of time, at $1.05 \mathrm{~V}$; (b) influence of potential, for $20 \mathrm{~h}$.
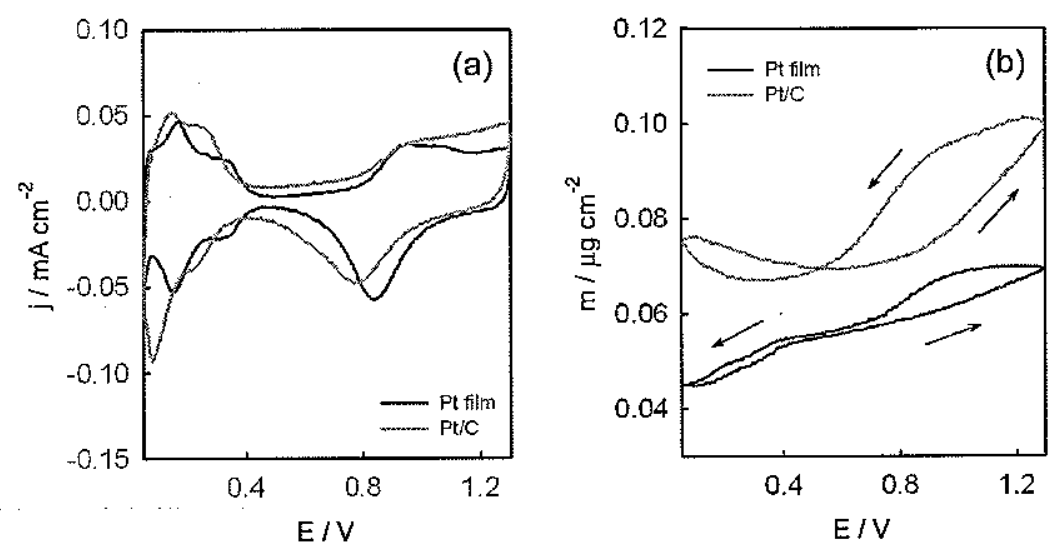

Fig. 5 Cyclic voltammogram (a) of $\mathrm{Pt}$ and $\mathrm{Pt} / \mathrm{C}$ per square centimetre of real electrochemical surface active area of $\mathrm{Pt}$ and QCM mass signal, (b) for $\mathrm{Pt}$ and $\mathrm{Pt} / \mathrm{C}$ taken at a scan rate of $50 \mathrm{mV} \mathrm{s}^{-1}$ in $1 \mathrm{M} \mathrm{HClO}_{4}$ at room temperature.

figures, the cyclic voltammogram as well as the mass change for a platinum film deposited on gold is plotted for comparison, to understand the carbon contribution in the $\mathrm{CV}$ and mass signal.

In comparison with a platinum thin film electrode which is plotted on the same graph, the cyclic voltammogram of $\mathrm{Pt}$ on carbon support shows a higher double layer capacity, which is typical for the large carbon surface in the $\mathrm{Pt} / \mathrm{C}$ electrode. The oxidation of platinum in $\mathrm{Pt} / \mathrm{C}$ starts at a slightly lower potential, and is subsequently reduced at a lower potential in the cathodic scan. This is caused by the higher susceptibility of small platinum particles to oxidation in comparison to bulk platinum [33]. When the potential is scanned from 0.45 to $1 \mathrm{~V}$, the mass of both electrodes, $\mathrm{Pt}$ and $\mathrm{Pt} / \mathrm{C}$, increases due to hydroxyl adsorption on $\mathrm{Pt}$ and following oxidation of the electrode surface. The mass signal of the $\mathrm{Pt} / \mathrm{C}$ electrode is composed by the contributions of platinum as well as of carbon. In absolute terms, the mass gain in this potential range amounts to around $0.5 \mu \mathrm{g}$. Comparison of the QCM graphs on the carbon support and the platinum, one can conclude that in $\mathrm{Pt} / \mathrm{C}$, half of the mass gain can be attributed to the reversible adsorption of oxygen on the carbon support, according to Eqs. (2) and (3).

In the cathodic scan, a mass decrease is observed between 0.45 and $0.05 \mathrm{~V}$ for $\mathrm{Pt}$, which could be attributed to the desorption of hydroxyl ions [15]. For $\mathrm{Pt} / \mathrm{C}$, the mass of electrode is found to increase, as in the case of the carbon support discussed before.

\subsubsection{Potentiostatic QCM Experiments of Platinum on Carbon with Characterisation by Cyclic Voltammetry (CV) and OLEMS}

The mass change versus time, as observed for the $\mathrm{Pt} / \mathrm{C}$ electrodes at $80^{\circ} \mathrm{C}$ and $0.95,1.05$ and $1.15 \mathrm{~V}$ are shown in Figure 6. Already in a qualitative way, the mass versus time signal shows a large variation depending on the potential. Because the contributions of both platinum as well as the carbon support are measured simultaneously, the mass change can be caused by several processes taking place with different rates: $\mathrm{Pt}$ oxidation and later dissolution and carbon oxidation followed by its corrosion. At these conditions, unsupported platinum was found to become fully oxidised and starts to dissolve after $10 \mathrm{~h}$ [15].

To discriminate between the processes on platinum and carbon, the potential was switched off at several intervals for taking two cyclic voltammograms at a scan rate of $50 \mathrm{mV} \mathrm{s}^{-1}$ in the potential range from 0.05 to $1.3 \mathrm{~V}$, as displayed in Figure 7 for $1.05 \mathrm{~V}$.

The oxide reduction peaks in the first cathodic scan, starting immediately from the potential hold, as shown in Figure $7 a$, indicate that the depth of the oxide layer grows with 

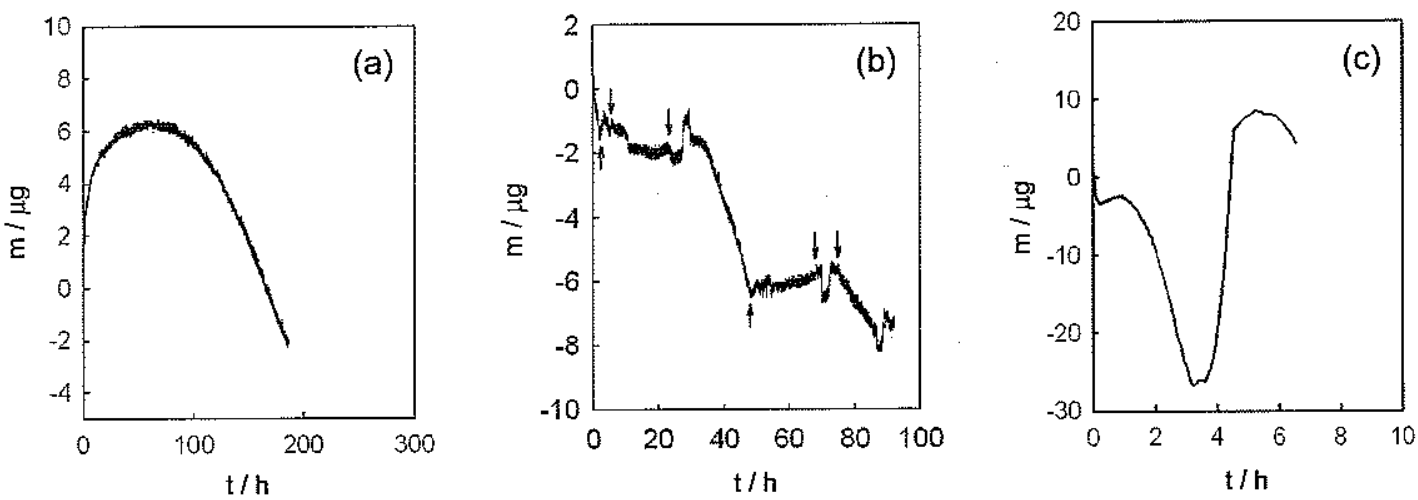

Fig. 6 Time dependence of the electrode mass measured at $0.95,1.05$ and $1.15 \mathrm{~V}$ for $\mathrm{Pt} / \mathrm{C}$ and $80^{\circ} \mathrm{C}$ (a) $0.95 \mathrm{~V}$ (b) $1.05 \mathrm{~V}$ (c) $1.15 \mathrm{~V}$.

potential hold time. Especially comparing the platinum oxide after $23.5 \mathrm{~h}$ with that after $2 \mathrm{~h}$ : while the reduction peak in the second scan (Figure $7 \mathrm{~b}$ ) after $23.5 \mathrm{~h}$ shifted to a higher value, the reduction peak in the first scan moved to lower values after $23.5 \mathrm{~h}$, i.e. the oxide produced during $23.5 \mathrm{~h}$ is more difficult to reduce than that after $2 \mathrm{~h}$, although the particle size has grown, as concluded from the shift of the oxide reduction to a higher potential.

From the hydrogen adsorption regions of the second $\mathrm{CVs}$ in Figure $7 \mathrm{~b}$, the surface area of the platinum in the electrode can be calculated at the various stages of the potentiostatic experiment. The loss of surface area is displayed in Figure 8a as a function of time.

From the second CVs in Figure $7 \mathrm{~b}$, it can be noted that the platinum oxide reduction peak potentials change at the subsequent intervals of exposure to $1.05 \mathrm{~V}$. The values of these oxide reduction peak potentials are shown as a function of time in Figure $8 \mathrm{~b}$. The oxide reduction peak potential reaches a maximum after $23 \mathrm{~h}$, suggesting an increase in the average $\mathrm{Pt}$ particle size. It is well known from previous studies that the platinum oxide reduction potential decreases with decreasing platinum particle size [34, 35]. In principle, this observed increase of particle size can occur when Pt dissolves and re-deposits on surrounding Pt particles, i.e. following the
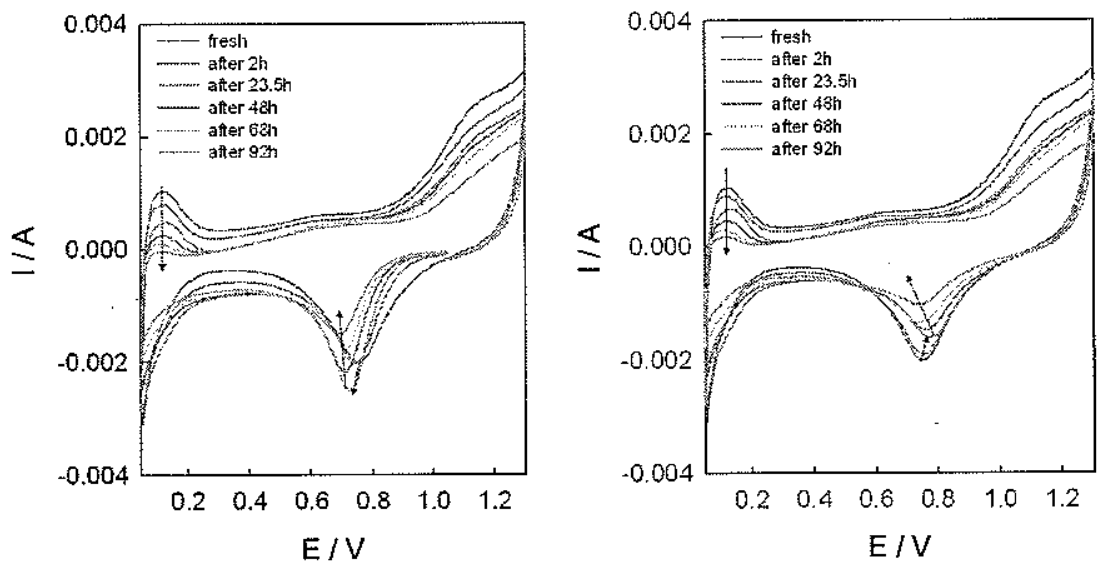

Fig. 7 Cyclic voltammograms taken at various intervals during exposure of $\mathrm{Pt} / \mathrm{C}$ to $1.05 \mathrm{~V}$ and $80^{\circ} \mathrm{C}$. (a) First scan; (b) second scan.
Ostwald ripening mechanism [36]. However, this experiment is conducted at such a high potential that the re-deposition of Pt will likely not take place. Therefore, the increase in the average $\mathrm{Pt}$ particle size can be explained by a loss of small $\mathrm{Pt}$ particles in the catalyst layer by their dissolution, while the larger particles remain unaffected. After $23 \mathrm{~h}$, the peak potential starts to shift in negative direction, indicating that the average size of the $\mathrm{Pt}$ particles reduces by dissolution of the remaining particles.

In the first $4 \mathrm{~h}$, the platinum surface area first drops and then increases again. This is unlikely to be linked to the platinum particle size. More likely, the decrease of the platinum surface area in the first two hours is associated to the poisoning of platinum surface by organic species, stemming from oxidation of the carbon support, to quinone-like species. In the next two hours, these carbon deposits are oxidised to $\mathrm{CO}_{2}$ leading to accessibility of the platinum for hydrogen adsorption. The potential excursion during the first scan of the CV is too short for cleaning the platinum. This assumption is supported by the relation between the charge of the platinum oxide reduction peak with time, giving a continuously declining line. Whereas hydrogen adsorption on platinum is extremely sensitive to poisoning, the platinum oxide formation is much less susceptible to it. Overall, the trend of the Pt surface area is declining with increase in potential hold time, both taken from the charge associated with hydrogen adsorption and desorption as well as that associated with platinum oxide formation and reduction.

The series of observations being the decrease in the platinum surface area, in combination with the shift of the platinum oxide reduction peak first to higher potentials, and then subsequently to lower potentials, was observed in nearly all experiments, provided the experimental time was long enough to pass the maximum in peak potential of the platinum oxide reduction. 

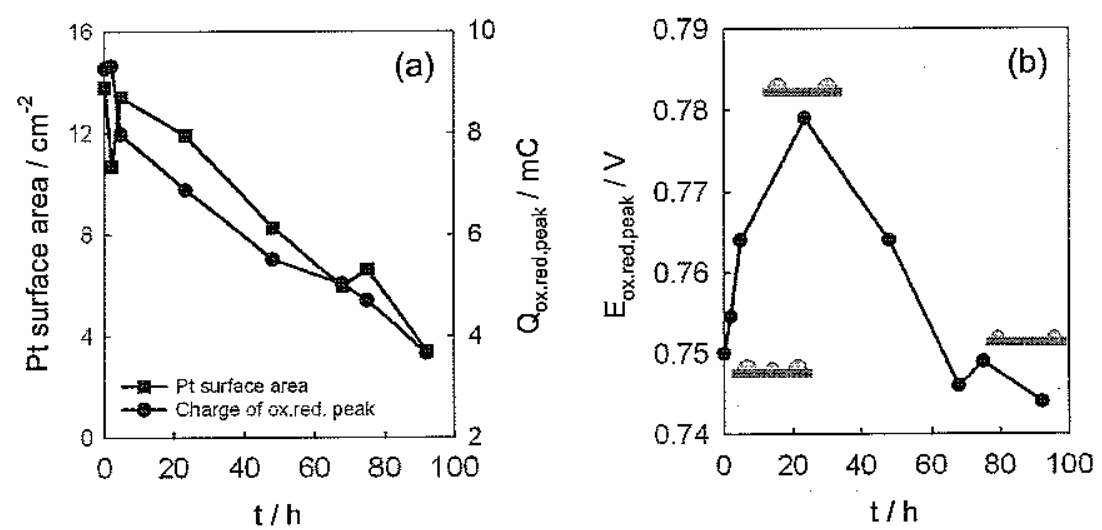

Fig. 8 Time dependence of the charge of the oxide reduction peaks (a) and Pt surface area (a) calculated from the second $C V_{s}$, which are taken during the exposure to $1.05 \mathrm{~V}$ and $80^{\circ} \mathrm{C}$. (b) Time dependence of the potential of the oxide reduction peaks in the second $\mathrm{CVs}$, which are taken during the exposure to $1.05 \mathrm{~V}$ and $80^{\circ} \mathrm{C}$.

A relation between the observed decrease in the platinum surface area and the particle size could be envisioned in the following way, illustrated in Figure $8 \mathrm{~b}$. As shown in Figure $8 \mathrm{~b}$, during the upward shift of the platinum oxide reduction peak potential, the small platinum particles dissolve, leading to an increase in average particle size. The following downward shift is linked to the shrinking of the particles, as the platinum dissolves from the surface of the particle.

The particle size distributions, as determined from the TEM pictures, taken from a fresh electrode as well as from a second electrode exposed to $1.05 \mathrm{~V}$ for $118 \mathrm{~h}$, as shown in Figure 9, confirm this explanation: the distribution of the particles shift to smaller particles after long exposure to $1.05 \mathrm{~V}$ at $80^{\circ} \mathrm{C}$. The average particle size of the freshly prepared electrode amounted to $4.0 \pm 1.2 \mathrm{~nm}$, while that of the electrode exposed to $1.05 \mathrm{~V}$ and $80^{\circ} \mathrm{C}$. for $118 \mathrm{~h}$ amounted to $3.0 \pm 1.4 \mathrm{~nm}$.

In Figure 10, the TEM pictures of a large section of the electrode are shown for the fresh electrode and that exposed to $1.05 \mathrm{~V}$ at $80^{\circ} \mathrm{C}$ for $118 \mathrm{~h}$. It can be clearly seen that the density of the particles in the fresh electrode is much higher than that in the electrode exposed to $1.05 \mathrm{~V}$ at $80^{\circ} \mathrm{C}$ for $118 \mathrm{~h}$, confirming the disappearance of platinum during the potentiostatic hold experiment.

Based on the measured platinum surface area in the fresh electrode, being $15.4 \mathrm{~cm}^{2}$, one can estimate the total corresponding amount of platinum on the QCM electrode. Taking the average particle size $d_{\mathrm{Pt}}$ of $4 \mathrm{~nm}$, the fraction of platinum atoms exposed to the surface FE is 0.31 , using [37]:

$\mathrm{FE}=\frac{1.25 \mathrm{~nm}}{d_{\mathrm{Pt}}(\mathrm{innm})}$

Taking a platinum atom density of $1.31 \times 10^{15}$ atoms per $\mathrm{cm}^{2}$ [38], $15.4 \mathrm{~cm}^{2}$ corresponds to a total platinum amount of $21 \mu \mathrm{g}$ in the electrode. The observed loss of platinum surface area, and correcting for the smaller average particle size of $3 \mathrm{~nm}$ after exposure to $1.05 \mathrm{~V}$ at $80^{\circ} \mathrm{C}$, corresponds to $18 \mu \mathrm{g}$ of dissolved platinum in $118 \mathrm{~h}$. Over the whole time period, the dissolution rate amounted to $0.15 \mu \mathrm{g} \mathrm{h}^{-1}$ or $0.01 \mu \mathrm{g} \mathrm{h}$ ${ }^{1} \mathrm{~cm}^{-2}$ of the original platinum surface area. The dissolution rate calculated for the electrode shown in Figure 8 , is the same: a loss of $15.5 \mu \mathrm{g}$ of dissolved platinum in $92 \mathrm{~h}$ which, based on the original surface area of $13.8 \mathrm{~cm}^{2}$, corresponds to a dissolution rate of $0.01 \mu \mathrm{g} \mathrm{h}^{-1} \mathrm{~cm}^{-2}$ of the original platinum surface area.

The $\mathrm{CO}_{2}$ production during the first and second scan after holding the potential of a $\mathrm{Pt} / \mathrm{C}$ electrode for $30 \mathrm{~min}$ at $1.15 \mathrm{~V}$, is shown in Figure 11. The $\mathrm{CO}_{2}$ production on the electrode is zero after holding the potential at $1.15 \mathrm{~V}$ for $30 \mathrm{~min}$, and only takes off, again at around $0.6 \mathrm{~V}$ in the positive scan, after complete reduction of the platinum. In the second scan, the production of $\mathrm{CO}_{2}$ is far higher in the cathodic scan, showing that a prolonged oxidation time is necessary to make platinum inactive for the corrosion of carbon. Comparing Figures 11 and 2, shows that the $\mathrm{CO}_{2}$ formation in the pla-

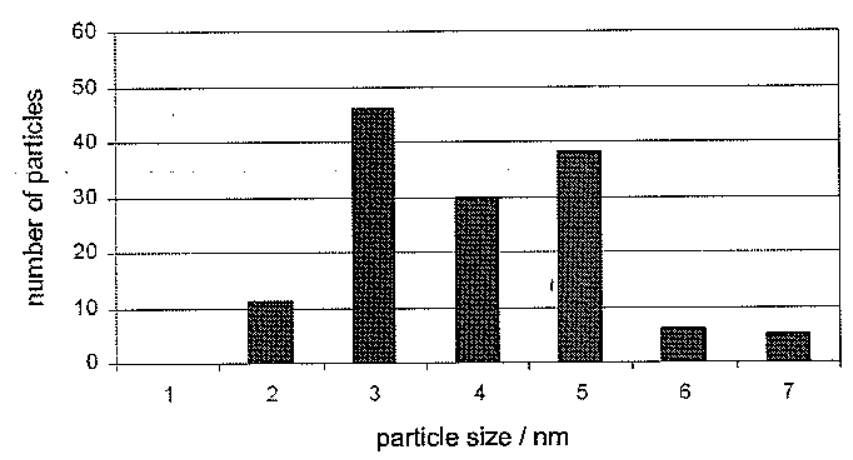

(a)

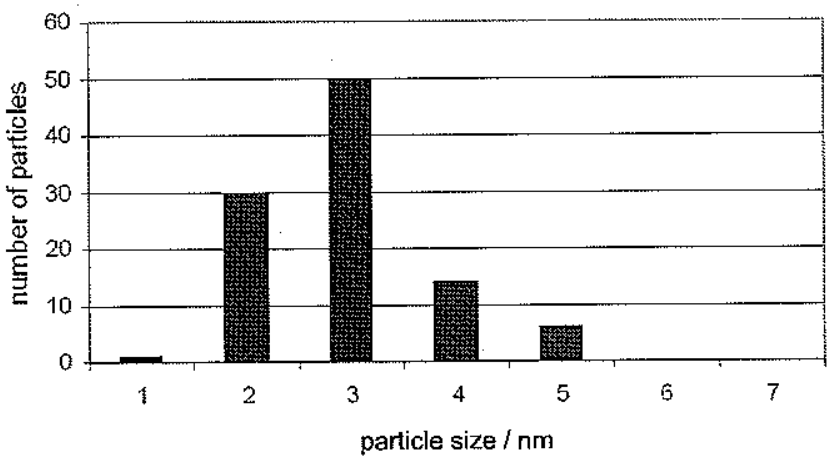

(b)

Fig. 9 Particle size distribution as determined by TEM in the $\mathrm{Pt} / \mathrm{C}$ catalyst, after electrode preparation (a) and after $118 \mathrm{~h}$ exposure to $1.05 \mathrm{~V}$ and $80^{\circ} \mathrm{C}(b)$. 


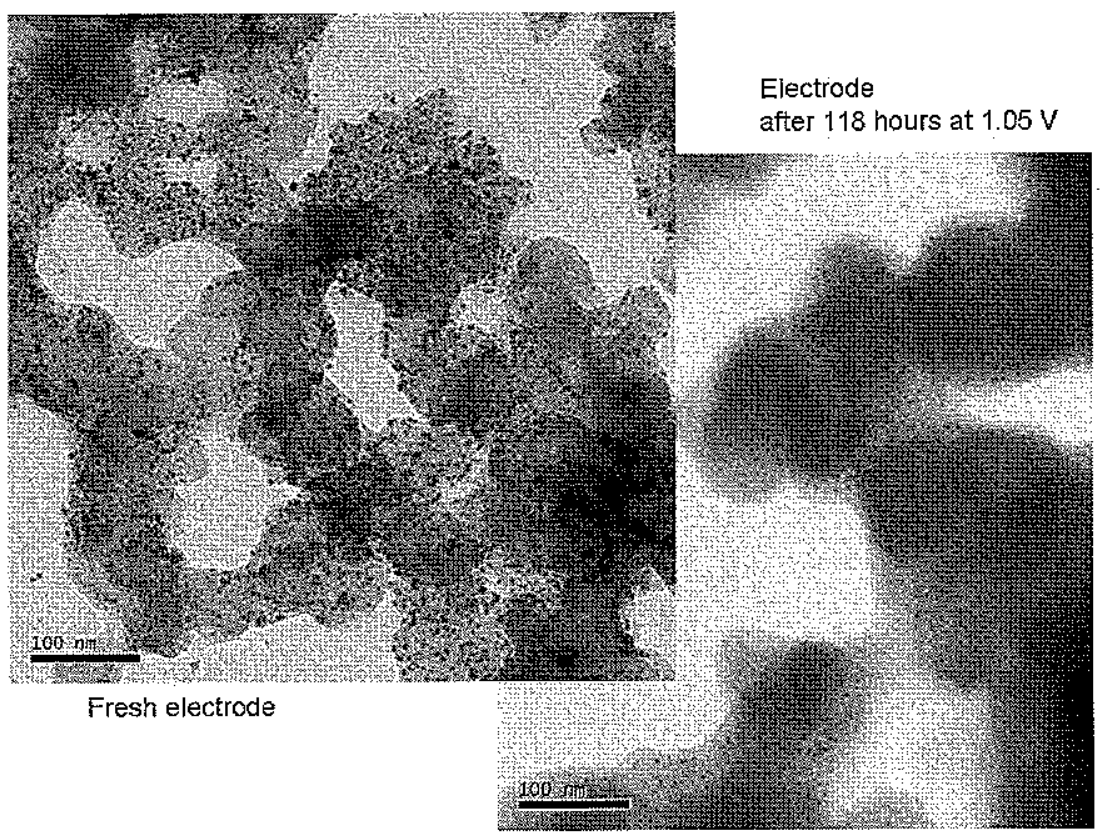

Fig. $10 \mathrm{TEM}$ pictures the $\mathrm{Pt} / \mathrm{C}$ catalyst, after electrode preparation (leff) and after $118 \mathrm{~h}$ exposure to $1.05 \mathrm{~V}$ and $80^{\circ} \mathrm{C}$ (right). tinum on carbon catalyst starts at a potential around $500 \mathrm{mV}$ lower than on the carbon support without platinum.

Table 1 summarizes for 80 and $60^{\circ} \mathrm{C}$, the observed decrease in platinum surface area for various potentials, and the observations with respect to the shift of oxide reduction peak potential, giving an indication on whether dissolution is the cause of this decrease.

From Table 1, it follows that the rate of decrease in platinum surface area increases with temperature and potential. In the first experiment at $1.15 \mathrm{~V}$ and $80^{\circ} \mathrm{C}$, an extremely fast decrease in the platinum surface area was observed, which could not be reproduced in two subsequent experiments. In the two latter experiments, the contact between the electrode and the QCM substrate was lost after around $24 \mathrm{~h}$, which might indicate that the corrosion of carbon leads to loss of the integrity of the electrode, rendering a poor electrical contact.
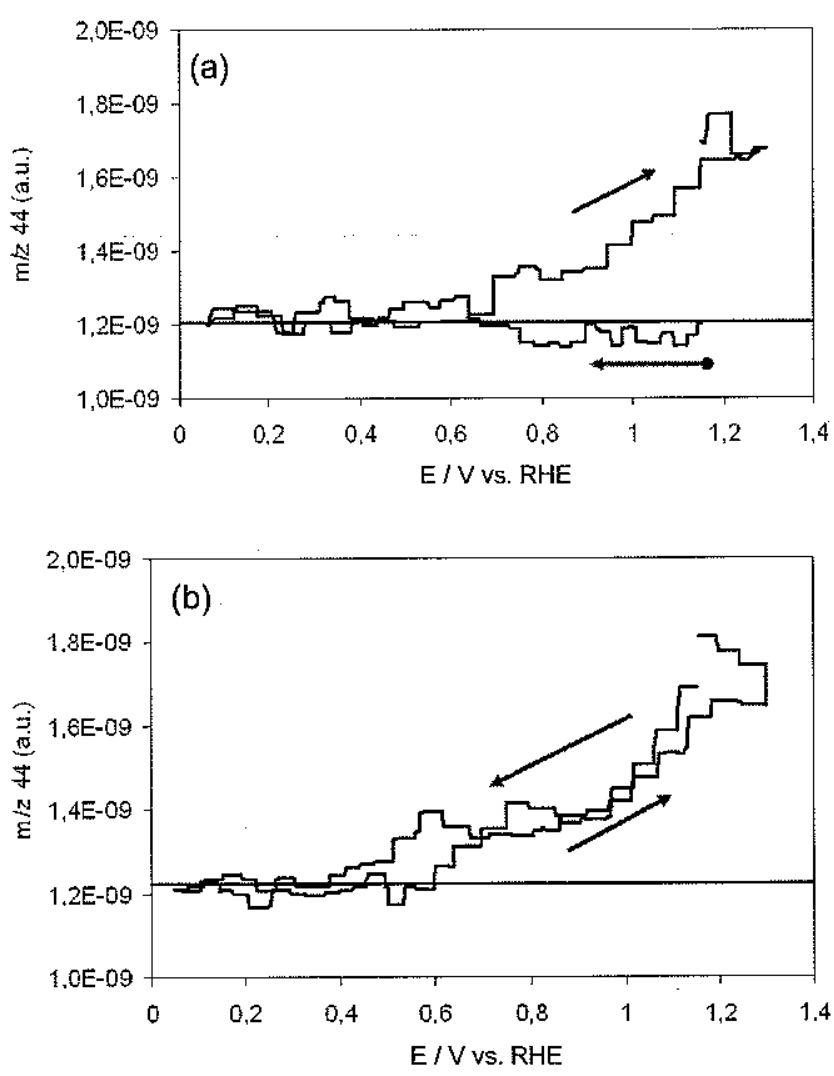

Fig. 11 OLEMS of $\mathrm{Pt} / \mathrm{C}$, taken at a scan rate of $10 \mathrm{mV} \mathrm{s}^{-1}$ in $1 \mathrm{M} \mathrm{HClO}_{4}$ $80^{\circ} \mathrm{C}$, after 30 min potentiostatic hold at $1.15 \mathrm{~V}$. (a) First scan, immediately after potentiostatic hold; (b) second scan.

\subsection{Summary and Comparison of Results with Literature}

\subsubsection{Platinum}

The observations in this work, show that for the conditions applied, i.e. potentiostatic hold, at $1.05 \mathrm{~V}$ and higher at 60 and $80^{\circ} \mathrm{C}$, the electrochemical surface area of platinum in platinum carbon catalysts decreases in most cases linearly in time. Depending on the conditions, this leads to a loss of $40-90 \%$ of the original surface area in a limited number of hours.

Such a loss of surface area is reported in many papers occurring during PEMFC operation, e.g. [7, 13, 39]. In [13] changes, observed for PEMFC MEA's exposed to operation to OCV conditions for $2,000 \mathrm{~h}$, were an increase in average particle size and a detectable band of platinum in the membrane. Also in [14], platinum was detected in the membrane after fuel cell operation, without extensive OCV exposures. These observations indicate that indeed platinum in the PEMFC is soluble under operating conditions, especially but not only at OCV. The dissolved platinum migrates to the anode, and is redeposited in the membrane once the hydrogen concentration is such that it can lead to the reduction of $\mathrm{Pt}^{2+}$ to metallic platinum. At the same time, part of the platinum is redeposited already on the cathode catalyst, leading to an increase in particle size following the mechanism of Ostwald ripening.

The conditions in this work are such that the redeposition of dissolved platinum is less likely to occur. In contrast to the PEMFC conditions, no cross over hydrogen is present to reduce the platinum ions to metallic platinum, which generally explains the platinum band in the membrane. At the 
Table 1 Observed loss of platinum surface area, rate of loss of surface area and platinum oxide reduction peak potential in $\mathrm{Pt} / \mathrm{C}$ elecirodes, as determined from the second by cyclic voltammogram affer potentiostatic hold at various conditions.

\begin{tabular}{|c|c|c|c|c|c|c|c|}
\hline 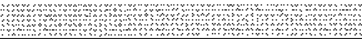 & $60.071 .05 \mathrm{~V}$ & $80 . \mathrm{C} / 105 \mathrm{~V}$ & $80 \circ \mathrm{C} / 105 \mathrm{~V}$ & $80 \% \mathrm{C} / 15 \mathrm{~V}$ & $80 . \mathrm{C} / 115 \mathrm{~V}$ & $80 \% \mathrm{O} / 15 \mathrm{~V}$ & $80 \% \mathrm{C} / 125 \mathrm{~V}$ \\
\hline $\begin{array}{l}\text { Rate of ptarea change } \\
\left(\mathrm{cm}^{2} \mathrm{pt} / \mathrm{cm}^{2} \mathrm{Ptfresh} / \mathrm{h}\right)\end{array}$ & 00016 & 0.00849 & 0.0072 & 0.30044 & 0.014 & 0.015 & 00779 \\
\hline $\begin{array}{l}\text { Total Joss of pt surfucearea } \\
\text { observed (as percentage } \\
\text { of orignalararea) }\end{array}$ & $40 \% 262 \mathrm{H}$ & $71 \% 1192 \%$ & $83 \% \mathrm{ml} 1 \mathrm{~h}$ & $90 \% \operatorname{moh}$ & $24 \%$ in 17 & $30 \% \mathrm{~m} 20 \mathrm{~h}$ & $85 \% \ln 6 \mathrm{~h}$ \\
\hline E no ked fresh electrode & 0.74 & 0.75 & 073 & 0.76 & 0.71 & 0.76 & 0.76 \\
\hline E pto, red maximum (after hours) & $076(90)$ & $078(24)$ & $0.75(45)$ & $0.77(1)$ & $072(17)$ & $0.80(20)$ & $076(1)$ \\
\hline E RTO ird - Minimum (after hours) & $075(262)$ & $074(92)$ & $073(118)$ & $0.72(6)$ & (a) & (1) & $074(7.5)$ \\
\hline
\end{tabular}

(a) Electrical contact lost within first $24 \mathrm{~h}$.

same time, the volume of the perchloric acid electrolyte (230 $\mathrm{mL}$ for an electrode area of $1.37 \mathrm{~cm}^{2}$ ) in this work is such that the local platinum concentration stays below the equilibrium concentration which provokes redeposition: $10 \mu \mathrm{g}$ dissolved platinum corresponds to $210^{-9} \mathrm{M} \mathrm{Pt}^{2+}$ well below the equilibrium concentration of $10^{-7} \mathrm{M} \mathrm{Pt}^{2+}$ reported by [13]. In the PEMFC cathode, the electrolyte present is Nafion, in which the platinum concentration will very quickly pass the saturation concentration, which will provoke redeposition and so leads to Ostwald ripening.

\subsubsection{Carbon}

Carbon was shown to be stable both at $60^{\circ} \mathrm{C}$ and $80^{\circ} \mathrm{C}$ up to $1.05 \mathrm{~V}$. At $1.15 \mathrm{~V}$ and higher, the mass of carbon shows a rapid drop after a period of time were the surface first is oxidised to quinone/hydroquinone type of species and higher oxidation states. The sharp drop in mass is likely to be caused by $\mathrm{CO}_{2}$ formation.

Comparing the mass-time curves for carbon with those of platinum on carbon, it seems that the presence of platinum accelerates both the oxidation as well as the corrosion of carbon. Either the slow build up phase of oxygenated species leading to an increase in mass of carbon is completely absent, as at $80^{\circ} \mathrm{C}$, or the mass increase is faster in the presence than in its absence, as at $60^{\circ} \mathrm{C}$ and $1.05 \mathrm{~V}$.

As shown by on-line electrochemical mass spectrometry, under dynamic conditions $\mathrm{CO}_{2}$ formation occurs when the potential is higher than $1.1 \mathrm{~V}$. From the dynamic OLEMS measurements, it followed that $\mathrm{CO}_{2}$ production in the presence of platinum can be measured at potentials of $0.6 \mathrm{~V}$ and higher, compared to $1.1 \mathrm{~V}$ and higher in the absence of platinum. After prolonged exposure of the electrode to $1.15 \mathrm{~V}$, leading to the deep oxidation of platinum, it becomes inactive for the catalysis of carbon corrosion.

The catalytic effect of platinum on the corrosion of carbon, shown in this work, is in agreement with those published by Willsau and Heitbaum [17], as well as by Roen et al. [29], who used the dynamic measurement of $\mathrm{CO}_{2}$ production by a mass spectrometer as well. In all these experiments, the production of $\mathrm{CO}_{2}$ from the carbon support was detected at much lower potentials than when platinum is absent. Ball et al. [23] concluded that platinum does not accelerate the corrosion of carbon, from experiments performed at $1.2 \mathrm{~V}$, and at the same time discarding the corrosion current during the first $60 \mathrm{~s}$. This can be in agreement with the observation in this work, showing that platinum, after exposure to $1.15 \mathrm{~V}$ for $30 \mathrm{~min}$, is not active for $\mathrm{CO}_{2}$ production. It is likely that in the first $60 \mathrm{~s}$ discarded by Ball, $\mathrm{CO}_{2}$ was produced as long as platinum was in the metallic state; but when passivated by an oxide layer, became inactive for the corrosion of carbon.

\section{Conclusion}

The stability of $\mathrm{Pt} / \mathrm{C}$ electrodes was studied at elevated temperature by a QCM, CV, OLEMS and TEM.

At $80^{\circ} \mathrm{C}$, a rapid decrease of the platinum surface area could be observed at potentials of $1.05 \mathrm{~V}$ and higher. This loss of surface area is attributed to the dissolution of platinum, which under the conditions applied, is not redeposited.

In the absence of platinum, the carbon support can be corroded provided the potential is high enough and the time of exposure is long enough. In the presence of metallic platinum, the corrosion of carbon is accelerated.

\section{Acknowledgements}

This work was part of the Dutch EOS-LT PEMLIFE project, contract no. EOSLT01029 and EOS-LT Consortium PEMFC, contract nos. EOSLT 06005 and EOSLT 07005 supported by the Ministry of Economic Affairs.

Michiel de Heer (Energy research Centre of the Netherlands), Serdar Celebi and Ad Wonders (University of Technology, Eindhoven) are acknowledged for their technical support.

\section{References}

[1] F.A. de Bruijn, V. A. T. Dam, G. J. M. Janssen, Fuel Cells $2008,8,3$.

[2] Y. Shao-Horn, P. J. Ferreira, G. J. la O', R. Makharia, S. Kocha, H. Gasteiger, Sym. on Durability and Reliability of Low-T Fuel Cell and Fuel Cell Systems, Los Angeles, 2005, Oct. 16th-21st.

[3] J. Yu, T. Matsuura, Y. Yoshikawa, N. Islam, M. Hori., Electrochem. Solid-State Lett. 2005, 8, A156. 
[4] D. Liu, S. Case, J. Power Sources 2006, 162, 521.

[5] J. Xie, D. L. Wood III, D. M. Wayne, T. A. Zawodzinski, P. Atanassov, R. L. Borupa, Electrochem. Soc. 2005, 152, 104.

[6] J. Xie, D. L. Wood III, K. L. More, P. Atanassov, R. L. Borup, Electrochem. Soc. 2005, 152, 1011.

[7] S. J. C. Cleghorn, D. K. Mayfield, D. A. Moore, J. C. Moore, G. Rusch, T. W. Sherman, N. T. Sisofo, U. Beuscher, J. Power Sources 2006, 158, 446.

[8] C. H. Paik, G. S. Saloka, G. W. Graham, Electrochem. Solid-State Lett. 2007, 10, 39.

[9] S. D. Knights, K. M. Colbow, J. St-Pierre, D. P. Wilkinson, J. Power Sources 2004, 127, 127.

[10] A. Taniguchi, T. Akita, K. Yasuda, Y. Miyazaki, J. Power Sources 2004, 130, 42.

[11] Z. Nagy, H. You, Electrochim. Acta 2002, 47, 3037.

[12] R. L. Borup, J. R. Davey, F. H. Garzon, D. L. Wood, M. A. Inbody, J. Power Sources 2006, 163, 76.

[13] P. J. Ferreira, G. J. la $\mathrm{O}^{\prime}$, Y. Shao-Horn, D. Morgan, R. Makharia, S. Kocha, H. A. Gasteiger, Electrochem. Soc. 2005, 152, A2256.

[14] E. Guilminot, A. Corcella, F. Charlot, F. Maillard, M. Chatenet, J. Electrochem. Soc. 2007, 154, B96.

[15] V. A. T. Dam, F. A. de Bruijn, Electrochem. Soc. 2007, 154, B494.

[16] X. Wang, R. Kumar, D. J. Myers, Electrochem. Solid-State Lett. 2006, 9, A225.

[17] J. Willsau, J. Heitbaum, Electroanal. Chem. Interfac. Electrochem, 1984, 161, 93.

[18] D. A. Stevens, J. R. Dahn, Carbon 2005, 43, 179.

[19] M. F. Mathias, R. Makharia, H. A. Gasteiger, J. J. Conley, T. J. Fuller, C. J. Gittleman, S. S. Kocha, D. P. Miller, C. K. Mittelsteadt, T. Xie, S. G. Yan, P. T. Yu, Electrochem. Soc. Interface 2005, 14, 24.

[20] D. A. Stevens, M. T. Hicks, G. M. Haugen, J. R. Dahn, Electrochem. Soc. 2005, 152, A2309.

[21] P. Ascarelli, V. Contini, R. Giorgi, J. App. Phys. 2002, 91, 4556.
[22] M. Cai, M. S. Ruthkosky, B. Merzougui, S. Swathirajan, M. P. Balogh, S. E. Oh, J. Power Sources 2006, 160, 977.

[23] S. C. Ball, S. L. Hudson, D. Thompsett, B. Theobald, J. Power Sources 2007, 171, 18.

[24] Y. Shao, G. Yin, Y. Gao, P. Shi, Electrochem. Soc. 2006, 153, 1093.

[25] K. Kinoshita, J. Bett, Carbon 1973, 11, 403.

[26] A. Reiser, L. Bregoli, T. W. Patterson, J. S. Yi, J. D. Yang, M. L. Perry, T. D. Jarvi, Electrochem. Solid-State Lett. 2005, 8, A273.

[27] N. Giordano, P. L. Antonucci, E. Passalacqua, L. Pino, A. S. Arico, K. Kinoshita, Electrochim. Acta 1991, 36, 1931.

[28] Z. Siroma, K. Ishii, K. Yasuda, Y. Miyazaki, M. Inaba, A. Tasaka, Electrochem. Com. 2005, 7, 1153.

[29] L. M. Roen, C. H. Paik, T. D. Jarvi, Electrochem. SolidState Lett. 2004, 7, A19.

[30] G. Vatankhah, J. Lessard, G. Jerkiewicz, A. Zolfaghari, B. E. Conway, Electrochim. Acta 2003, 48, 1613.

[31] A. H. Wonders, T. H. M. Housmans, V. Rosca, M. T. M. Koper, J. Appl. Electrochem. 2006, 36, 1215.

[32] H. Binder, A. Kohling, A. G. Sandstede, Electrochim. Acta 1972, 17, 873.

[33] O. V. Cherstiouk, P. A. Simonov, E. R. Savinova, Electrochim. Acta 2003, 48, 3851.

[34] Y. Takasu, Y. Fujii, K. Yasuda, Y. Iwanaga, Y. Matsuda, Electrochim. Acta 1989, 34, 453.

[35] T. Frelink, W. Visscher, J. A. R. van Veen, J. Electroanal. Chem. 1995, 382, 65.

[36] P. N. Ross, in Catalyst Deactivation, Chemical Industries Series, Vol 30 (Eds., E. E. Petersen, A. T. Bell), Marcel Dekker Inc., New York, 1987, Ch. 7, p. 165.

[37] J. J. F. Scholten, A. P. Pijpers, A. M. L. Hustings, Catal. Rev. Sci. Eng. 1985, 27, 151.

[38] S. Trasatti, O. A. Petrii, J. Electroanal. Chem. 1992, 327, 353.

[39] Y. Shi, A. Horky, O. Polevaya, J. Cross, 2005 Fuel Cell Seminar Abstracts, Palm Springs, Courtesy Associates, 2005. 